\title{
Тутыхина С.H. \\ Особенности уравнений состояния г-образных схем замещения воздушного трансформатора
}

Санкт-Петербургский политехнический университет Петра Великого (Россия, Санкт-Петербург)

doi: $10.18411 / \mathrm{sr}-10-08-2017-24$

idsp: 000001:sr-10-08-2017-24

$\left(L_{1}, L_{2}\right)$, связанными между собой взаимной индуктивностью М (рис. $\left.1, \mathrm{a}\right)$.

Воздушный трансформатор представляет собой цепь с двумя индуктивностями

a)

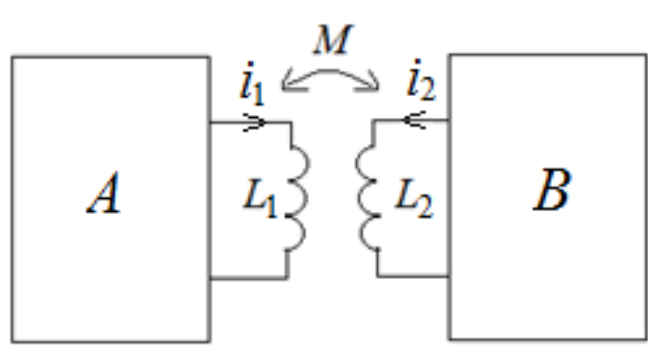

б)

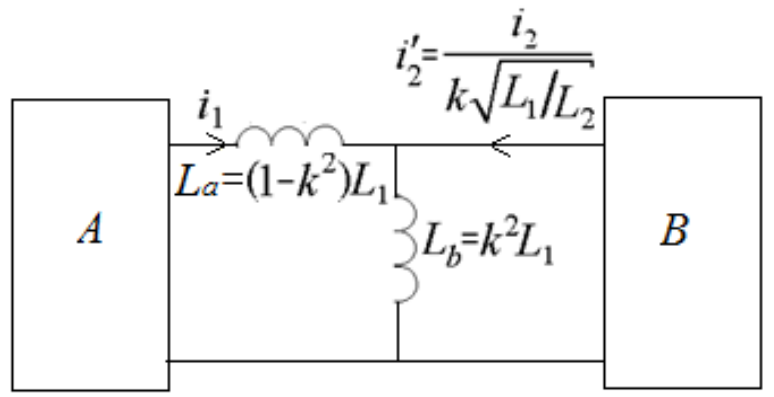

Puc.1

В учебной литературе динамическим процессам в данных схемах не удаляется должного внимания[1-5]. Исследования этих процессов удобнее всего производить с помощью уравнений состояния:

$$
\frac{d \mathbf{x}}{d t}=\mathbf{A x}+\mathbf{B} \cdot \mathbf{f}(t), \quad \mathbf{x}(0)=\mathbf{x}_{0} .
$$

Однако получение матрицАи $\mathrm{B}$ дляцепей со взаимной индуктивностью значительно сложнее, чем дляцепей без взаимной индуктивности.

Цель данной работы - ознакомление с г-образной схемой замещения таких цепей (рис.1,б). Эта схема, по-видимому впервые полученная д.т.н. М.А.Шакировым в [6], существенно облегчает анализ динамических режимов в исходных цепях (рис.1,a). В [6] представлен также оригинальный вывод г-образной схемы на основе разработанной автором методики переноса элементов схемы через узлы, сечения и вдоль контуров [712].Вторая цель работы - сравнение уравнений состоянияисходной и эквивалентной схем на примере анализа переходного процесса в простейшей цепи второго порядка сложности (рис.2,a). Поставленная цель реализуется сравнением уравнений состояния исходной и преобразованной цепей (рис.2,a,б).

a)

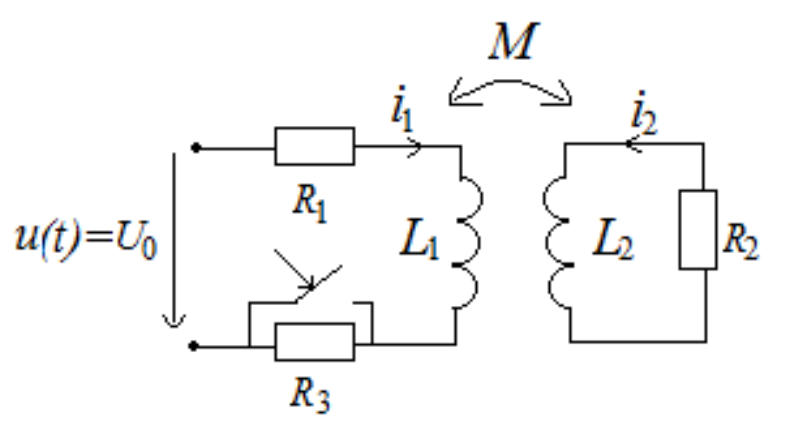

б)

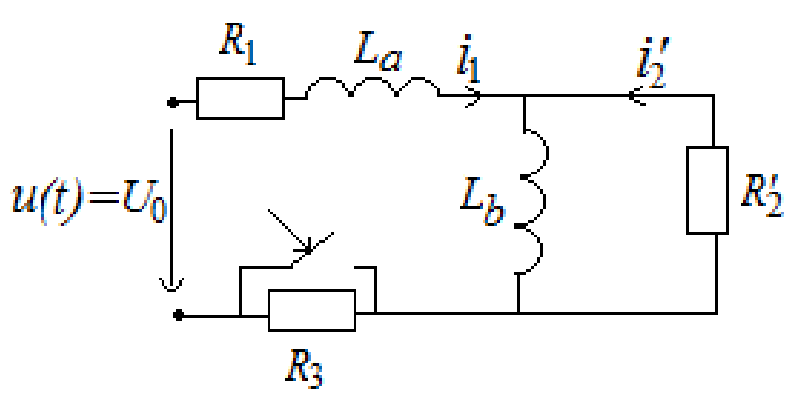


Для простоты рассмотрим случай, когда $u(t)=U_{0}=$ const при следующих данных цепи (рис.2,a):

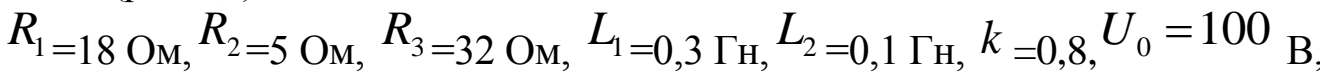

$$
\begin{aligned}
& \text { где } k=M / \sqrt{L_{1} L_{2}} \text {-коэффициент связи. Решение выполним поэтапно. }
\end{aligned}
$$

Этап 1.Получение уравнения состояний исходной цепи с взаимной индуктивностью (рис.2,a).Как отмечалось, получение матрицАи В вданном случае требует усилий и имеет весьма сложный вид:

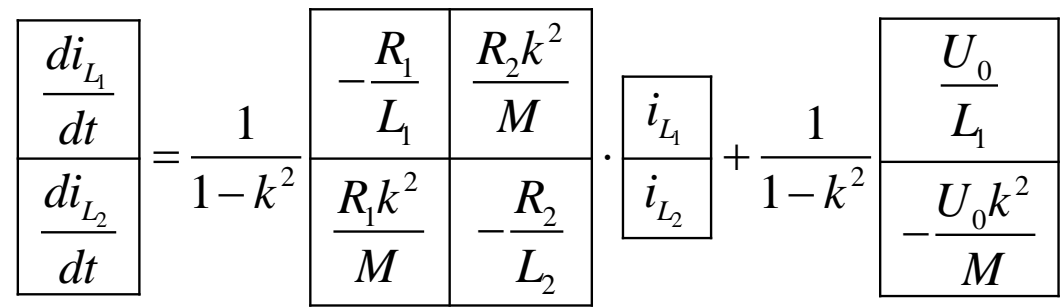

при следующих начальных условиях:

$$
\begin{array}{|c|}
\hline i_{L_{1}}(0) \\
\hline i_{L_{2}}(0) \\
=
\end{array}=\begin{gathered}
\frac{U_{0}}{R_{1}+R_{3}} \\
0 \\
0
\end{gathered} .
$$

В численном выражении имеем:

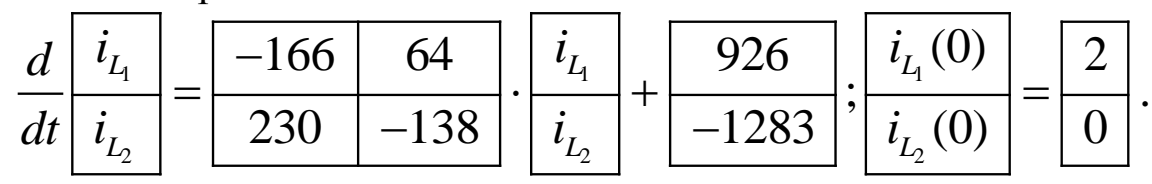

Этап 2.Получение уравнения состояния для г-образной эквивалентной схемы замещения(рис.2,б). В [6] представлены два варианта развязки взаимной индуктивности с получением г-образной и Г-образнойэквивалентных схем. Здесь используется г-образный вариант схемы замещения, показанный на рис.1,би рис.2,б.В отличие от предыдущего случая уравнения состояния этой схемы легко выводятся и имеют достаточно простой вид:

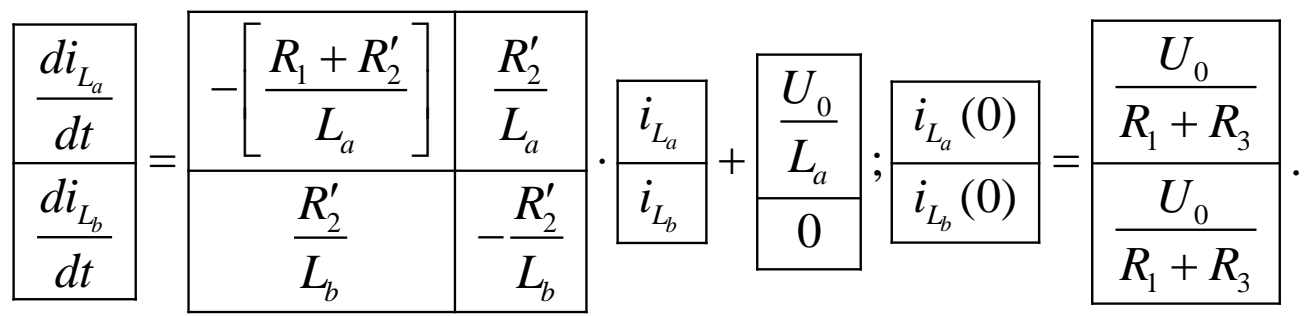

В численном выражении имеем:

$$
\frac{d}{d t} \begin{array}{l|}
i_{L_{a}} \\
\hline i_{L_{b}}
\end{array}=\begin{array}{|c|c|}
\hline-255,5 & 89 \\
\hline 50 & -50 \\
\hline i_{L_{b}}
\end{array} \cdot \begin{array}{|l|}
\hline i_{L_{a}} \\
\hline 0
\end{array} ; \quad \begin{array}{c|}
926 \\
\hline i_{L_{b}}(0) \\
\hline 2 \\
\hline
\end{array} .
$$




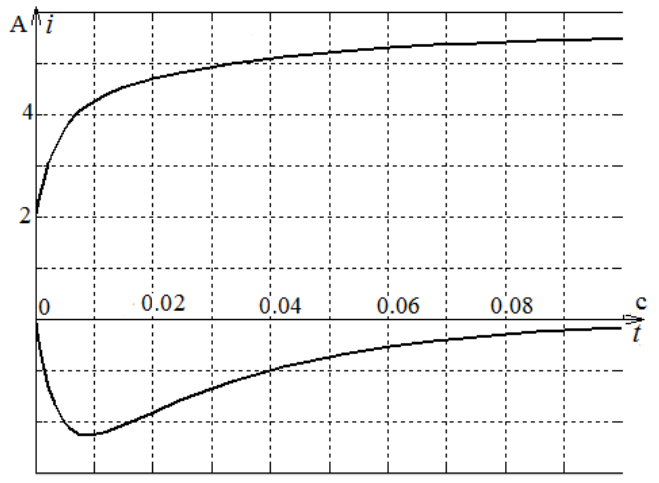

Рис. 3

Как видно, начальные условия вг-образной схеме замещения отличаются от начальных условий в исходной цепи. В г-образной схеме замещения ток ${ }^{L_{1}}$ не изменяется, тогда как ток, проходящий через сопротивление $R_{2}^{\prime}$, является приведенным:

$$
i_{2}^{\prime}=i_{L_{a}}-i_{L_{b}} ; \quad i_{2}=k \sqrt{\frac{L_{1}}{L_{2}}} i_{2}^{\prime} .
$$

Естественно, что кривые переходного процесса в обеих схемах (рис.2,а и б) совпадают (рис.3).

\section{Заключение}

1. г-образная схема замещения, значительно облегчает анализ динамических процессов в цепях, содержащих воздушный трансформатор.

2. Уравнения состояния и начальные условия этой схемы замещения принципиально отличаются от уравнений состояния и начальных условий исходной цепи с взаимной индуктивностью.

3. Чем сложнее цепь с воздушным трансформатором, тем в большей степени сказывается преимущество г-образной схемы замещения, благодаря простоте её уравнений.

4. Необходимо аналогичное исследование для Г-образной схемы замещения цепей с взаимной индуктивностью.

$$
* * *
$$

1. Демирчян К.С., Нейман Л.Р., Коровкин В.Н., Чечурин В.Л. Теоретические основы электротехники: В 3х т. СПб.: Питер, 2003.

2. Теоретические основы электротехники: в 2 т. /Под ред. П.А.Ионкина/. М.: Высш. шк., 1976.

3. Бессонов Л.А. Теоретические основы электротехники. М.: Высш. шк., 1996. электрических цепей и электромагнитного поля.М.: Издательский центр "Академия", 2008.

4. Г.В.Зевеке, П.А.Ионкин, А.В.Нетушил, С.В.Страхов. Основы теории цепей. М.: Энергоатомиздат, 1989.

5. Бычков Ю.А., Золотницкий В.М., Чернышев Э.П. Основы теории электрических цепей. СПб.: Изд-во «Лань»,2002.

6. Шакиров М.А. и др. Практикум по ТОЭ. ч.1. Под ред.Шакирова М.А.СПб.: Изд-во Политехн. ун-та, 2017, 260 стр.

7. Шакиров М.А. и др. Практикум по ТОЭ. ч 2. Под ред.Шакирова М.А.СПб.: Изд-во Политехн. ун-та, 2017, 230 стр.

8. Шакиров М.А. Преобразование и диакоптика электрических цепей. Л.: Изд-во ЛГУ, 1980.

9. Шакиров М.А. Методы анализа сложных электрических цепей: Л.: Из.-во ЛПИ, 1984.

10. ШакировМ.А. Теоретические основы электротехники. Тензоры в ТОЭ, электродинамика, теория относительности.СПб.: Изд-воПолитехн. ун-та, 2011.

11. Шакиров М.А.Декомпозиционные алгоритмы анализа электромагнитных полей. Л.: Изд-во ЛГУ, 1990 (первая глава книги посвященадиакоптике цепей).

12. Шакиров М.А. Теоретические основы электротехники. Новые идеи и принципы. Схемоанализ и диакоптика. Спб.: Изд-во СПбГТУ, 2001. 